K A N D A I

\begin{tabular}{|l|l|l|}
\hline Volume 16 & No. 2, November 2020 & Halaman 231-244 \\
\hline
\end{tabular}

\title{
MOTIF GENDER DALAM TIGA CERITA RAKYAT TOLAKI (Gender Motif in Three Tolakinese Folktales)
}

\author{
Zakiyah Mustafa Husba, Heksa Biopsi Puji Hastuti, Rahmawati, \& Uniawati \\ Kantor Bahasa Provinsi Sulawesi Tenggara \\ Jalan Haluoleo, Kompleks Bumi Praja Anduonohu, Kendari, Indonesia \\ Telepon (0401)3135289, 3135287; Faksimile (0401) 3135286 \\ Pos-el: zakiyah.mustafa@kemdikbud.go.id
}

(Diterima: 23 Januari 2020; Direvisi: 7 Juli 2020; Disetujui: 2 November 2020)

\begin{abstract}
Stories that involve female characters contain both genders as the primary motive and subordinate motives. The problem raised in this study was how the gender motives were contained in the three Tolaki folktales and aimed to uncover the gender motives contained in the "Wekoila", "Haluoleo", and "Pasaeno" stories. Tolaki folklore was obtained through interview techniques and library research. Data were analyzed qualitatively by using LeviStrauss structural analysis approach by breaking down myths. Then motive analysis was carried out with a focus on gender motives. The results of the analysis were known that the Wekoila story showed the gender motive in which female character was placed in the superior position. Haluoleo's story contained the gender motive in which there were no fixed concepts for women positioning. Meanwhile, Pasaeno's story showed the gender motive in which female characters were placed as whose rights were ignored. Thus it was concluded that the gender motives in the three Tolakinese folktales were lack of uniformity.

Keywords: gender motives, folktale, Tolakinese
\end{abstract}

\begin{abstract}
Abstrak
Cerita yang melibatkan tokoh perempuan ini memuat motif gender baik sebagai motif utama maupun motif bawahan. Permasalahan yang diangkat dalam penelitian ini ialah bagaimana motif gender yang terkandung dalam tiga cerita rakyat Tolaki dan bertujuan mengungkap motif gender yang terdapat di dalam cerita "Wekoila”, "Haluoleo", dan "Pasaeno". Data berupa cerita rakyat Tolaki diperoleh melalui teknik wawancara dan penelusuran pustaka. Data dianalisis secara kualitatif dengan menggunakan pendekatan analisis struktural Levi-Straus dengan mengurai mitem-mitem cerita. Selanjutnya, analisis motif dilakukan dengan fokus motif gender. Dari hasil analisis diketahui bahwa cerita "Wekoila" menunjukkan bahwa tokoh perempuan diposisikan superior. Cerita "Haluoleo" memuat bahwa tidak ada konsep baku bagi pemosisian perempuan. Sementara itu, cerita "Pasaeno" menunjukkan tokoh perempuan yang ditempatkan sebagai pihak yang diabaikan hak-haknya. Dengan demikian, motif gender dalam ketiga cerita rakyat Tolaki ini disimpulkan tidak memiliki keseragaman.
\end{abstract}

Kata-kata kunci: motif gender, cerita rakyat, Tolaki

DOI: 10.26499/jk.v16i2.2104

How to cite: Husba, Z. M., Hastuti, H. B. P., Rahmawati, Uniawati (2020). Motif gender dalam tiga cerita rakyat Tolaki. Kandai, 16(2), 231-244 (DOI: 10.26499/jk.v16i2.2104)

PENDAHULUAN

Dalam sebuah cerita, motif merupakan alur penggerak. Alur yang dijalankan oleh sejumlah tokoh menguntai dan menjadi media penyampai gagasan pengarang kepada pembacanya. Pelibatan tokoh perempuan 
dalam sebuah cerita dapat menuntun penikmatnya-baik pembaca dalam sastra tulis maupun pendengar dalam sastra lisan-pada sebuah motif yang dapat dikaitkan dengan gender. Dari perspektif yang terdapat dalam motif gender ini dapat diketahui bagaimana laki-laki dan perempuan diposisikan dalam kehidupan masyarakat yang menjadi latar ceritanya. Dalam penelitian ini, motif gender yang diungkap ditempatkan dalam konsep pemahaman komunal orang Tolaki.

Dalam budaya orang Tolaki dikenal sebuah cerita yang memiliki tokoh sentral perempuan, yaitu cerita "Wekoila". Cerita yang diyakini sebagai salah satu versi asal muasal orang Tolaki ini menampilkan sosok perempuan hebat yang menunjukkan kemampuannya di ruang publik. Cerita "Pasaeno", yang diterima relatif lebih pendek dibanding dua cerita lainnya, menampilkan satu tokoh perempuan, yaitu ibunda Pasaeno. Ada juga cerita "Haluoleo" yang menyajikan sepak terjang kepahlawanan Haluoleo. Di dalam perjalanan pengembaraannya, Haluoleo tidak terlepas dari hadirnya tokoh-tokoh perempuan. Terhitung tiga tokoh perempuan yang dapat dijadikan dasar penelaahan motif gender di dalam cerita ini, yaitu ibu Haluoleo, Putri Haluoleo, dan Putri Wolio. Ketiga cerita ini memuat keterlibatan tokoh-tokoh perempuannya dalam beragam alur dan karakter. Tokoh-tokoh perempuan ini memberikan gambaran bagaimana perempuan dan laki-laki bersinergi dalam entitas kehidupan.

Suku Tolaki bercorak patriarki. Garis keturunan diperhitungkan dari pihak laki-laki. Cukup mengejutkan bahwa dalam budaya patriarki yang kental justru dikenal cerita perempuan super seperti Wekoila. Berangkat dari corak budaya Tolaki yang bersifat patriarki serta muatan cerita yang beragam, menarik dilakukan penelaahan mengenai motif gender yang terkandung di dalamnya. Permasalahan yang menjadi fokus penelitian ini ialah bagaimanakah motif gender yang terdapat dalam tiga cerita rakyat Tolaki? Penelitian bertujuan mengungkap motif gender yang terdapat dalam cerita "Wekoila", "Haluoleo", dan "Pasaeno". Cerita tentang Wekoila dan Haluoleo tertambat dalam memori kolektif orang Tolaki sebagai kisah heroisme, sedangkan pada kisah Pasaeno tercatat ingatan mengenai kisah yang lebih personal. Ketiga cerita rakyat ini memiliki nilai historis bagi orang Tolaki. Ketiga nama ini, Wekoila, Haluoleo, dan Pasaeno diabadikan menjadi nama-nama ruang publik di Kota Kendari. Dengan karakter tokoh yang beragam, ketiga cerita ini memberikan peluang telaah yang dapat mewakili pemahaman gender.

Bagi orang Tolaki pada masa lalu, hubungan kekerabatan yang berasal dari nenek moyang yang sama senantiasa dijaga agar tidak renggang (Faisal, 2014). Perempuan erat kaitannya dengan aspek kekerabatan, menyangkut proses reproduksi untuk regenerasi sehingga banyak mewarnai cerita-cerita. Kisah "Wekoila" pernah dikaji untuk memperoleh deskripsi representasi perempuan Tolaki. Hasil kajian menunjukkan bahwa perempuan Tolaki yang terepresentasi dalam tokoh Wekoila sebagai figur ideal perempuan Tolaki ialah bahwa suku Tolaki memosisikan perempuannya pada tempat yang penting dalam proses penerusan keturunan. Perempuan juga dianggap mampu berkiprah baik dalam ranah domestik maupun publik dengan tetap mengindahkan tuntutan memprioritaskan suami karena pencapaian positifnya tidak lepas dari dukungan dan perlindungan suami serta anggota keluarga laki-laki lainnya 
(Hastuti, 2014a). Hastuti juga mengkaji pemosisian perempuan Tolaki melalui mitos "Oheo" yang hasilnya ialah perempuan dalam keluarga Tolaki berada pada posisi terhormat dalam kaitannya dengan proses regenerasi keluarga. Perempuan Tolaki tidak tabu berada pada wilayah kerja nondomestik (Hastuti, 2014b). Penelitian kali ini mengambil fokus pada celah yang belum dikaji sebelumnya, yaitu motif gender yang termuat dalam cerita rakyat Tolaki.

\section{LANDASAN TEORI}

Pengklasifikasian sastra lisan mengacu pada pendapat William $\mathrm{R}$. Bascom, sebagaimana yang dikutip oleh Danandjaja (1984). Menurutnya, sastra lisan, khususnya cerita prosa rakyat, dapat dibagi dalam tiga golongan besar berikut.

1. Mite ' $m y t h$ ' merupakan kisah yang dianggap nyata terjadi dan bersifat suci dengan melibatkan dewa-dewi serta makhluk setengah dewa sebagai tokohnya. Peristiwa-peristiwa yang ada dalam kisah mite dipercaya terjadi tidak di dunia nyata.

2. Legenda 'legend', sebagaimana mite, legenda pun dianggap benar-benar terjadi. Perbedaannya, legenda dianggap bersifat keduniawian, tidak sesuci mite. Selain itu, peristiwaperistiwa di dalamnya dianggap terjadi di dunia yang menjadi tempat hidup manusia sekarang. Tokoh yang terlibat, selain manusia, biasanya juga dibantu oleh makhluk-makhluk ajaib.

3. Dongeng (folktale) merupakan cerita rakyat yang oleh masyarakat dianggap sebagai ciptaan imajinatif atau tidak dianggap sebagai hal yang benarbenar terjadi.

Adapun ciri-ciri cerita rakyat dalam teori Bascom antara lain adalah penyebarannya secara lisan, bersifat anonim atau tidak diketahui siapa penciptanya, merupakan milik bersama dalam suatu masyarakat, dan tidak memiliki bentuk. Selanjutnya dijelaskan fungsi cerita rakyat sebagai berikut.

a. Cerita rakyat menjadi refleksi harapan sebuah kelompok masyarakat.

b. Cerita rakyat yang disampaikan berulang secara lisan menjadi media legitimasi atas norma dan tata aturan yang ada dalam kelompok masyarakat.

c. Cerita rakyat berfungsi sebagai alat pendidikan budi pekerti kepada anakanak. Melalui cerita yang disampaikan secara lisan secara turun temurun, nilai-nilai tata krama tertanam dalam pikiran generasi pelanjut.

d. Cerita rakyat berfungsi sebagai kontrol sosial agar segala aturan dipatuhi oleh anggota kelompoknya.

Melalui cerita, para orang tua menyisipkan tradisi, kebiasaan, cara pandang, dan pengetahuan yang berlaku di dalam masyarakatnya (Rahmawati, 2007). Selain ciri-ciri cerita rakyat yang perlu dipahami dalam melakukan penelitian ini, motif cerita pun perlu mendapat pemahaman yang memadai. Motif sebagai anasir terkecil dalam sebuah cerita mempunyai daya tahan lama dalam tradisi. Motif juga dapat diartikan dengan unsur-unsur suatu cerita (narratives elements). Motif teks suatu cerita adalah unsur dari cerita tersebut yang menonjol dan tidak biasa sifatnya (Danandjaja, 1986).

Di dalam sebuah cerita rakyat termuat mimpi atau angan-angan komunal pendukungnya. Untuk mengungkap mimpi apa yang terkandung di dalam cerita rakyat perlu dilakukan analisis yang mengkaji relasi antarelemen yang terdapat di dalam struktur cerita (Nitayadnya, Karsana, Pranawengtyas, \& Rahma, 2016). 


\section{Motif Gender dalam Cerita Rakyat}

Ada berbagai motif yang dapat ditemukan dalam cerita rakyat. Motif yang terdapat di dalam sebuah cerita rakyat dapat berupa motif utama (Yetti, 2014). Dengan demikian, sebuah cerita rakyat dapat saja mengandung motif lain sebagai pengiring atau motif penyerta. Motif merupakan elemen cerita atau narrative element (Danandjaja, 1986). Motif cerita dapat mengacu pada benda, konsep, perbuatan, atau hal lainnya.

Taum (2011) membuat pengelompokan motif yang biasa dijumpai dalam cerita-cerita rakyat. Ada lima kelompok motif yang diklasifikasikan menurut unsur yang dominan dalam cerita. Berikut klasifikasi motif menurut Taum.

1. Motif benda menampilkan bendabenda yang dominan dan memiliki peran sentral dalam sebuah cerita. Benda bisa berupa tongkat wasiat, benda ajaib, tumbuhan atau pohon tertentu, tanah liat, benda-benda angkasa, dan sebagainya.

2. Motif hewan. Pada cerita yang memuat motif ini, ada peran penting yang dimainkan oleh tokoh berupa hewan tertentu dan umumnya memiliki keunikan. Sebagai contoh, cerita yang melibatkan tokoh hewan berupa kuda terbang, buaya siluman, hewan dengan bentuk fisik yang tidak biasa seperti singa berkepala manusia, hewan raksasa, hewan yang bisa berbicara, burung phoenix, ular naga, ayam jantan, dan sebagainya.

3. Motif yang berupa konsep. Cerita dengan motif konsep memuat suatu pengertian yang menjadi aturan dalam sebuah kelompok masyarakat. Konsep yang ditampilkan dapat berupa larangan, tabu, kewajiban, dan sebagainya.

4. Motif perbuatan, misalnya sebuah cerita yang menampilkan suatu perbuatan yang menjadi bagian penting di dalamnya. Perbuatan bisa berupa ujian ketangkasan, ujian pengetahuan, meminum minuman keras, pertemuan di suatu tempat, perpisahan, penyamaran, penghambaan, pertapaan, perjalanan melewati alam gaib, pertarungan dengan raksasa, dan sebagainya.

5. Motif penipuan menampilkan perbuatan "menipu" yang dilakukan satu tokoh kepada tokoh lainnya.

Dalam lima klasifikasi motif cerita rakyat yang ditawarkan Taum, motif gender masuk ke kelompok ketiga, yakni motif berupa konsep. Dalam hal ini, motif gender dalam cerita rakyat menjadi representasi konsep gender yang berlaku di dalam masyarakatnya. Gender, secara istilah konseptual, lebih menitikberatkan pada pemosisian laki-laki dan perempuan dalam peran dan fungsinya dalam masyarakat. Bagaimana pandangan masyarakat mengenai posisi perempuan dan bagaimana pula halnya pandangan mengenai posisi kaum lakilaki.

Selain klasifikasi motif Taum, dikenal juga indeks motif yang dicetuskan oleh Stith Thompson. Thompson membuat daftar indeks motif meliputi motif-motif dan submotif yang terdapat di dalam cerita. Indeks motif Thompson mengklasifikasikan motif dalam kelompok-kelompok yang diberi kode (dari A10 hingga Z350). Motif yang terdapat dalam indeks Thompson di antaranya ialah motif mitologi, motif hewan, motif tabu, motif magis, motif kematian, motif dunia lain, motif raksasa, motif tes, motif bijaksana dan bodoh, motif penipuan, motif pemulihan nasib, motif menahbiskan masa depan, motif peluang dan nasib, motif masyarakat, dan motif sifat hidup. Berangkat dari pemahaman gender sebagai pemosisian laki-laki dan perempuan dalam peran dan fungsinya 
dalam masyarakat, kelompok motif yang sesuai dalam indeks motif Thompson adalah motif masyarakat-tatanan sosial lainnya dengan kode F190 (Thompson, 1958).

\section{Strukturalisme Lêvi-Strauss}

Untuk lebih menelisik bagianbagian yang mengandung persamaan, kemiripan atau bahkan perbedaan dari motif-motif cerita yang ada, digunakan teori strukturalisme Levi-Strauss. Pada teori ini, struktur teks naratif dianggap ekuivalen dengan struktur dalam kalimat. Penyejajaran ini didasarkan atas dua hal. Pertama, teks naratif memuat satu entitas yang memiliki makna (meaningful whole) sehingga dianggap dapat merealisasikan dan mengekspresikan pemikiran pengarangnya. Pandangan ini ekuivalen dengan sebuah kalimat yang mampu menjadi media ekspresi pikiran pembuatnya. Kedua, sebuah teks naratif diartikulasikan oleh bagian-bagian yang ada di dalamnya sebagaimana sebuah kalimat diartikulasikan oleh rangkaian kata-kata yang menyusunnya (AhimsaPutra, 2006).

Secara garis besar, Lêvi-Strauss memandang bahasa dan budaya sebagai hasil dari aneka aktivitas yang pada dasarnya mirip atau sama. Antara bahasa dan budaya terdapat semacam korelasi, bukan hubungan kausal, melainkan produk atau hasil dari aktivitas nalar manusia (Ahimsa-Putra, 2006). Korelasi tersebut memungkinkan seorang ahli bahasa bekerja sama dengan ahli antropologi untuk membandingkan ekspresi dan konsep mengenai waktu pada tataran bahasa dan pada tataran sistem kekerabatan atau relasi antarindividu.

Pada fenomena sosial dapat dijumpai sifat nirsadar. Hal inilah yang menarik perhatian Lêvi-Strauss, "the unconscious nature of collective phenomena". Ketertarikan ini menjurus kepada keingintahuan akan prinsipprinsip universal yang mendasari nalar manusia. Untuk mengetahui bahwa nalar mengikuti struktur tertentu dalam bekerja, perlu dianalisis berbagai aktivitas yang merupakan perwujudan dari nalar tersebut. Berbagai fenomena budaya pada dasarnya merupakan perwujudan dari nalar ini. Akan tetapi, setiap fenomena memiliki keunikan tersendiri sehingga membutuhkan pisau analisis yang berbeda-beda untuk menemukan strukturnya.

Salah satu contoh fenomena sosial yang sepenuhnya berada di bawah kendali nalar manusia ialah sistem kekerabatan dan perkawinan. Pernyataan ini mengundang silang pendapat dengan alasan bahwa pada tataran empiris banyak hal yang memengaruhi polanya sehingga muncul dan menjadi entitas budaya yang diterima sebagai fenomena sosial, seperti unsur-unsur dunia materi, demografi dan ekologi. Berdasarkan alasan inilah muncul pandangan bahwa gejala sosial tersebut tidak cukup kuat sebagai landasan untuk menunjukkan adanya kekangan struktural di balik fenomena budaya. Mitoslah fenomena budaya yang kemudian dipandang lebih dapat mewakili dalam upaya memperlihatkan adanya kekangan ini (Ahimsa-Putra, 2006).

Dalam konteks strukturalisme Lêvi-Srauss, yang dimaksud dengan mitos adalah dongeng. Mitos, bagi LêviStrauss, tidak harus dipertentangkan atau bahkan dipersamakan dengan alur sejarah yang benar-benar terjadi. Perbedaan makna dari keduanya semakin melebar dan sulit dipertemukan. Dua kelompok masyarakat yang berbeda bisa jadi memiliki perspektif berbeda pula mengenai suatu kisah mitos. Satu kelompok masyarakat menganggapnya sebagai sejarah dan kelompok lainnya 
menganggap kisah itu tidak nyata dan tidak pernah terjadi.

Begitu pula halnya pandangan mengenai kesakralan atau kesucian sebuah mitos, sangat bisa jadi berbedabeda antara satu kelompok masyarakat dan yang lainnya. Demikianlah hingga akhirnya konsep mitos dalam strukturalisme Levi-Strauss merujuk pada konsep dongeng dalam pengertian yang lebih umum (Ahimsa-Putra, 2006).

Dongeng merupakan suatu kisah yang bermula dari khayalan atau imajinasi manusia. Imajinasi ini terpicu tidak lain dari kejadian-kejadian atau pikiran mengenai keseharian manusia itu sendiri. Manusia dengan bebas boleh mengembangkan daya khayalnya melalui dongeng. Tidak ada larangan bagi manusia dalam penciptaan dongeng dengan beragam model latar, tokoh, dan alur. Apa saja boleh dikhayalkan terjadi dalam sebuah dongeng. Di dalam dongeng sah-sah saja dimunculkan tokoh, karakter, alur, dan latar yang tidak logis dan tidak bisa dijumpai dalam kenyataan. Sebagai contoh, kisah bidadari yang turun dari kayangan dengan menggunakan selendangnya. Dalam kehidupan sehari-hari, kejadian seperti ini belum pernah dijumpai secara nyata. Ada juga cerita mengenai kancil yang menipu harimau dan sekawanan buaya di sungai, cerita mengenai anak durhaka yang dikutuk dan berubah menjadi batu, cerita tentang labu yang berisi emas perhiasan, dan lain-lain. Secara logika, cerita-cerita ini tidak masuk akal. Namun, di dalam dongeng dimungkinkan dan diperbolehkan menjadi isi cerita.

Menurut Lêvi-Strauss, mitos, seperti halnya bahasa, terbentuk dari unit konstituen. Unit-unit ini menyerupai fonem, morfem, dan semem dalam bahasa. Namun, unit-unit dalam mitos berbeda satu dengan lainnya. Unit atau satuan-satuan dalam mitos berada pada tataran yang lebih kompleks dan disebut gross constituent units atau mythemes, yang diadaptasi penulisannya dalam sistem aksara bahasa Indonesia menjadi mitem. Mitem-mitem inilah yang harus didapatkan terlebih dahulu sebelum berusaha mengetahui makna sebuah mitos secara keseluruhan karena mitem ini merupakan unit terkecil dari cerita. Di sinilah kedudukan mitem yang berada pada posisi sebagai simbol dan tanda ditemukan.

Unit-unit terkecil mitos atau mitem adalah kalimat-kalimat atau kata-kata di dalam mitos yang menunjukkan relasi tertentu atau mempunyai makna tertentu. Ini berbeda dengan fonem yang memang betul-betul merupakan tanda yang tidak bermakna, tetapi bernilai. Oleh karena itu, sebuah mitem dapat dikatakan sebagai sebuah simbol karena dia memiliki acuan, mempunyai makna referential, tetapi di lain pihak mitem juga dapat ditanggapi sebagai sebuah tanda, yang mempunyai "nilai" dalam konteks tertentu. Jadi, sebuah mitem dapat ditanggapi sebagai simbol dan tanda sekaligus.

Ketika menganalisis mitos secara struktural, mitem-mitem yang ada di dalamnya perlu diperhatikan dan diperlakukan sebagai simbol dan tanda sekaligus. Metode ini akan memungkinkan kita melakukan analisis yang "objektif" atas mitos, sebagaimana halnya para ahli lingusitik yang telah berhasil menganalisis bahasa secara “objektif” karena mereka telah mencapai unit terkecil dari bahasa, yakni tanda atau fonem (Ahimsa-Putra, 2006).

\section{METODE PENELITIAN}

Metode yang digunakan dalam penelitian ini adalah metode deskriptifkualitatif dengan pendekatan analisis mitem dan pembacaan motif. Data berupa tiga cerita rakyat Tolaki 
diperoleh melalui penelusuran pustaka. Data pustaka berupa cerita rakyat yang sudah dituliskan. Cerita "Pasaeno" diperoleh dari buku Kebudayaan Tolaki yang ditulis oleh (Tarimana, 1993). Cerita "Wekoila" diambil dari data tesis Hastuti (2013) yang merupakan data pustaka yang sudah diverifikasi melalui wawancara dengan Bapak H. Muslimin Su'ud. Data cerita "Haluoleo" bersumber dari buku yang ditulis oleh Maranay (2009).

Data dianalisis dalam tiga tahap. Pertama dilakukan analisis mitem berdasarkan teori struktural LeviStrauss. Kedua, dari hasil analisis mitem selanjutnya dilakukan identifikasi motif gender yang terdapat di dalamnya. Analisis tahap tiga merupakan analisis perbandingan motif gender yang terdapat di dalam ketiga data mitos.

\section{PEMBAHASAN}

\section{Cerita "Wekoila", "Haluoleo", dan "Pasaeno"}

Sebagaimana yang telah disebutkan sebelumnya bahwa tiga cerita Tolaki yang menjadi data penelitian ini adalah cerita "Wekoila", "Haluoleo", dan "Pasaeno". Ketiga cerita ini terkait erat dengan kisah muasal suku Tolaki. Dengan berbagai versinya, dari tokoh-tokoh dalam ceritacerita inilah diyakini orang-orang Tolaki bermula. Mitos Wekoila mengisahkan seorang putri jelita yang turun dari kerajaan langit dengan mengemban misi mendamaikan tiga kerajaan yang sedang dalam peperangan. Wekoila menikah dengan Pangeran Ramandalangi, putra Raja Toramalangi. Wekoila sendiri tercatat dalam sejarah sebagai ratu yang pernah memerintah di Kerajaan Konawe dan menetapkan penggolongan kelas dalam masyarakat Tolaki (Melamba,
Akhdan, Bunggulawa, Daniel J. Amaludin, \& Sambari, 2013).

Cerita "Haluoleo" mengisahkan perjalanan hidup Haluoleo, seorang tokoh besar dalam kebudayaan Tolaki. Kisah ini merupakan kisah kepahlawanan. Di dalam kisahannya, mitos Haluoleo melibatkan beberapa tokoh perempuan yang cukup penting perannya. Cerita "Pasaeno" disampaikan secara singkat dalam wawancara. Demikian pula cerita yang diperoleh dalam bentuk tulisan, hanya memuat kisah kelahiran Pasaeno. Pasaeno adalah titisan dewa langit yang dikandung oleh Wesande akibat dia meminum air yang tergenang di atas sehelai daun di hutan.

Di dalam ketiga cerita terdapat tokoh perempuan. Pelibatan tokoh perempuan, baik dalam peran sentral maupun peran bawahan, membuka ruang menelisik motif gender di dalamnya.

\section{Analisis Mitem dan Motif Gender dalam Cerita "Wekoila"}

Cerita "Wekoila" melibatkan masa-masa sebelum Kerajaan Konawe terbentuk hingga masa penataan kerajaan baru tersebut. Berikut analisis mitem cerita "Wekoila".

1) Tiga kerajaan di tanah Konawe (Kerajaan Padangguni, Besulutu, dan Wawolesea) terlibat perang segitiga selama satu abad. Perang dimenangkan oleh Kerajaan Padangguni, tetapi kerajaan ini menjadi lemah akibat perang tersebut. Penduduk hidup terceraiberai.

2) Kerajaan Padangguni berikut dua kerajaan taklukannya mengalami masa kegelapan selama 200 tahun. Pada akhir masa kegelapan ini, dinasti Padangguni yang hidup adalah Mokole Toramalangi yang memiliki putra bernama Ramandalangi. 
3) Pada akhir masa kegelapan, seorang perempuan cantik jelita turun dari kayangan dengan membawa sebuah benda bernama kalo. Rakyat menyambut gembira kedatangan sang putri dan melaporkan kejadian ini kepada Mokole Toramalangi. Mereka menyebut perempuan ini dengan sebutan Sangia Ndudu ('dewa yang turun'). Mokole Toramalangi menamai perempuan itu Wekoila.

4) Rakyat sangat terkesan akan kalo, benda sakti milik sang putri.

5) Mokole Toramalangi menikahkan Wekoila dengan putranya, Ramandalangi.

6) Rakyat menobatkan Wekoila menjadi ratu 'mokole more' di Kerajaan Padangguni.

7) Dengan menggunakan kalo yang sakti, Wekoila menyatukan rakyat Kerajaan Padangguni, Besulutu, dan Wawolesea di dalam naungan satu pemerintahan kerajaan, yaitu Kerajaan Konawe.

8) Wekoila melakukan beberapa perubahan mendasar, yaitu: (1) memindahkan pusat kerajaan yang semula berada di Napo Olo-Oloho di tepi sungai Konaweeha ke daerah Ilaroni'i, Unaaha di Inolobu Nggadue; (2) menjadikan kalo sebagai dasar adat kebudayaan suku Tolaki di Kerajaan Konawe; (3) membagi wilayah Kerajaan Konawe menjadi beberapa wilayah pu'utobu wonua; (4) membentuk susunan aparat untuk membantu menjalankan roda pemerintahan; dan (5) membagi masyarakat di wilayah kerajaannya ke dalam tiga golongan stratifikasi.

9) Pada tahun 1158 (setelah delapan tahun memerintah) Wekoila menghilang bersama suaminya, kembali ke kayangan menjadi raja dewa di kayangan.
Motif gender sangat kental dalam cerita "Wekoila". Secara keseluruhan, cerita ini mengisahkan sepak terjang seorang perempuan hebat. Kedatangannya yang gaib terjadi dalam segmen pertengahan. Wekoila diyakini sengaja diutus oleh dewata untuk menyelamatkan kehidupan di bumi Padangguni. Meskipun Kerajaan Padangguni tampil sebagai pemenang dari perang saudara dengan Kerajaan Wawolesea dan Kerajaan Besulutu, kondisi yang semakin lemah membuat Padangguni menjadi seolah vakum tanpa pemimpin.

Dalam perspektif gender, pandangan kesetaraan mendominasi cerita dari awal hingga akhir. Kepercayaan kepada seorang perempuan untuk menjadi pemimpin ditunjukkan oleh tokoh Ramandalangi sebagai putra mahkota dan sekaligus juga sebagai suami Wekoila yang mendukung penobatan Wekoila menjadi ratu di Kerajaan Konawe. Perlu digarisbawahi bahwa yang menobatkan Wekoila menjadi ratu 'mokole more' bukanlah Raja Toramalangi, melainkan rakyat Kerajaan Padangguni. Wekoila memiliki karakter kuat sebagai perempuan sakti yang diutus dewa untuk membawa sinar terang bagi rakyat Padangguni dalam masa kegelapan mereka. Kalo yang dibawanya hingga sekarang diyakini sebagai simbol adat dan dasar kebudayaan Tolaki.

Dalam tugasnya, Wekoila digambarkan berhasil melaksanakan tugas sebagai pemimpin kerajaan dengan baik. Wekoila, dengan kesaktian kalonya, memerintahkan rakyat Padangguni pindah dari Abuki ke Unaaha. Mengiringi mobilisasi massa ini, Wekoila juga memindahkan pusat pemerintahan dari Napo Olo-Oloho, di tepi Sungai Konawe'eha, ke daerah Ilaroni'i, Unaaha, di Inolobu Nggadue. Di tangan Wekoila, bekas wilayah 
Kerajaan Padangguni, Besulutu, dan Wawolesea berhasil dipersatukan di bawah satu bendera kerajaan. Nama Konawe dipilih untuk menyebut hasil penyatuan tiga kerajaan tersebut.

Dalam kepemimpinannya, selain pemindahan pusat pemerintahan, Wekoila melakukan beberapa perubahan mendasar, yaitu menjadikan kalo sebagai dasar adat kebudayaan suku Tolaki di Kerajaan Konawe, membagi wilayah Kerajaan Konawe menjadi beberapa wilayah pu'utobu wonua, membentuk susunan aparat untuk membantu menjalankan roda pemerintahan, dan membagi masyarakat di wilayah kerajaannya ke dalam tiga golongan stratifikasi. Perubahan yang dilakukan oleh Wekoila ini dipegang teguh oleh suku Tolaki secara umum, terutama penentuan kalo sebagai dasar adat kebudayaan Tolaki dan pembagian strata sosial kemasyarakatan adat Tolaki. Sementara itu, pembagian wilayah puutobu wonua sejak kemerdekaan RI melebur pada sistem negara.

Suku Tolaki merupakan suku yang menganut garis patriarki, di dalam cerita "Wekoila" justru ditampilkan tokoh perempuan yang cakap dalam ranah publik. Dapat disimpulkan, meskipun garis keturunan yang dianut oleh suku Tolaki adalah garis laki-laki, di sana tidak dikenal pembedaan dalam aktualisasi diri bagi perempuan maupun laki-laki. Secara tradisional, suku Tolaki tidak mempermasalahkan jenis kelamin untuk memberi kesempatan berkiprah.

\section{Analisis Mitem dan Motif Cerita "Haluoleo"}

Cerita "Haluoleo" diawali dengan kisah kelahiran sang tokoh hingga perjalanan pengembaraannya dari satu tempat ke tempat lain. Berikut analisis mitem cerita Haluoleo.
1) Proses kehamilan yang berat dan terkesan tidak wajar karena ibu Haluoleo selama hamil hanya makan satu kali, yaitu hati anjing hitam, selain itu dia bertabiat bengis dan menyukai hal-hal kotor saat hamil. Namun, ketika menginjak hamil tua, ibu Haluoleo menyukai kesenian tradisi seperti mendengarkan dongeng dan nyanyian.

2) Proses kelahiran didahului dengan rasa sakit selama 8 hari 8 malam sehingga bayinya dinamakan Haluoleo. Ketika lahir, Haluoleo sudah menggenggam sebilah keris dari dalam kandungan ibunya.

3) Pada masa remajanya, karakter kepemimpinan Haluoleo paling menonjol di antara teman-teman sebayanya.

4) Haluoleo di Mekongga: memulai pengembaraannya, Haluoleo berangkat ke negeri Mekongga. Di sana ia membuat perahu dari kayu ndaumo lalu berlayar ke Towari, lalu lanjut menyusuri Konawe'eha hingga tiba di Olo-oloho (tanah Konawe).

5) Haluoleo di Konawe: di tanah Konawe, Haluoleo sangat berkuasa. Suatu ketika Haluoleo melakukan perjalanan ke Moronene. Dalam perjalanan, perahunya terbalik, anak perempuannya tenggelam. Putri Haluoleo ditahan oleh Raja I'Puritahi dengan tujuan agar ada juga berkah Haluoleo di bumi Konawe.

6) Haluoleo di Moronene: di bumi Moronene Haluoleo menikah dan memiliki putra. Haluoleo pergi ke To Mokole (Kabaena), untuk selanjutnya kembali bertualang menuju tanah Muna.

7) Haluoleo di Muna: Haluoleo menuju Muna untuk menemui ayahnya. Haluoleo menggantikan posisi ayahnya sebagai Raja Muna setelah 4 tahun tinggal di Muna. Raja Wolio mengumumkan sayembara untuk 
membunuh Labolondio dengan hadiah mempersunting putrinya.

8) Haluoleo di Wolio: Haluoleo mengikuti sayembara Raja Wolio dan mengalahkan Labolondio dengan taawu-nya. Haluoleo memotong kemaluan Labolondio.

9) Beberapa raja lain mengambil bagian tubuh Labolondio yang mati di tangan Haluoleo dan menunjukkannya kepada Raja Wolio dan mengatakan bahwa merekalah yang telah berhasil membunuh Labolondio. Akan tetapi, Raja Wolio lebih percaya Haluoleo yang membunuh Labolondio karena Haluoleo membawa kemaluan Labolondio sebagai buktinya.

10) Haluoleo menikah dengan putri Raja Wolio, lalu menjadi Raja Wolio.

Motif gender menjadi motif penyerta dalam sepanjang kisah Haluoleo. Diawali dengan sejarah kelahirannya, peran dan posisi ibu cukup memberikan ilustrasi motif gender pada seksi awal cerita ini. Seksi ini mengetengahkan posisi perempuan dalam aspek regenerasi nama keluarga. Perempuan diposisikan sebagai modal bagi kesinambungan keturunan. Perspektif gender yang terbaca pada seksi ini ialah adanya kerja sama antara laki-laki dan perempuan demi sebuah kelahiran generasi baru. Hal ini terlihat dari pengorbanan ibu Haluoleo yang digambarkan dalam kondisi psikis tidak menentu akibat kehamilannya dan pengorbanan ayah Haluoleo yang rela menerima perlakuan tidak wajar dari istrinya. Tidak terlihat adanya pemarginalan perempuan dalam segmen ini, ataupun sekadar upaya pemarginalan. Perempuan dalam segmen ini justru menempati posisi penting dan dihormati. Kodratnya sebagai perempuanlah yang menjadikannya istimewa.
Pada mitem 5 yang berisi cerita tentang pengembaraan pertama Haluoleo di tanah Konawe, terselip cerita tentang anak perempuannya. Cerita tentang anak perempuan Haluoleo ini memang tidak dominan, tetapi cerita inilah satu-satunya bagian yang menceritakan anak Haluoleo. Mengapa anak perempuan Haluoleo dalam segmen ini diceritakan secara khusus? Pada segmen lain (dalam mitem 6), pengungkapan kisah anak Haluoleo hanya diceritakan bahwa di tanah Moronene Haluoleo memiliki putra. Perbedaan porsi cerita ini menyiratkan sebuah pesan khusus. Perempuan, yang direpresentasikan oleh putri Haluoleo, memang diceritakan tenggelam dan pada akhirnya ditinggalkan oleh ayahnya. Akan tetapi, dalam delik cerita, anak perempuan ini diminta tinggal oleh Raja I'Puritahi dengan tujuan agar ada juga berkah Haluoleo di bumi Konawe. Dari tujuan Raja I'Putitahi yang diyakini sebagai sangia penguasa alam air ini, terbaca bagaimana seorang perempuan diposisikan sebagai bagian penting untuk menjadi penyambung kebaikan orang tuanya. Dalam perspektif gender, perlakuan Haluoleo (meninggalkan putrinya) tidak merupakan tindak pemarginalan. Justru, Haluoleo memercayai putrinya untuk tetap tinggal dan membawa berkah bagi bumi Konawe.

Pada segmen terakhir, bagian yang berisi cerita Haluoleo di tanah Muna dan Wolio, tokoh perempuan hadir dalam sosok putri Raja Wolio yang dijadikan hadiah sayembara kerajaan. Menarik untuk dicermati, bagaimana sesungguhnya posisi putri Raja Wolio pada penggalan kisah Haluoleo ini. Di satu sisi, dia diposisikan sebagai sesuatu yang berharga, yang layak diperjuangkan dengan kerja keras. Tidak sembarang orang dapat mempersunting sang putri. 
Di sisi lain, dapat juga dikatakan bahwa sebagai pribadi, sang putri tidak memiliki posisi tawar, bahkan untuk menentukan pilihan pendamping hidupnya. Dalam perspektif gender, ketidakbebasan ini dapat diartikan sebagai inferioritas perempuan. Perempuan tidak diberi kewenangan untuk menentukan sendiri nasibnya. Nasib seorang perempuan, dalam hal ini putri Raja Wolio, berada di tangan ayah dan para peserta sayembara. Dia tidak berhak menolak siapa pun yang menjadi pemenang sayembara menjadi suaminya. Bahkan, jika seandainya pemenang sayembara itu seorang yang dibencinya, sang putri tidak boleh membatalkan skenario pernikahan yang telah dirancang dalam rangkaian sayembara. Segmen ini menunjukkan pemosisian sang putri yang inferior seperti "barang" yang tidak berhak menolak dirinya dijadikan taruhan. Bahkan, untuk hal penting dalam fase kehidupannya, yaitu fase pernikahan yang seharusnya terjadi hanya sekali seumur hidupnya, ia harus rela diputuskan dalam sebuah sayembara.

\section{Analisis Mitem dan Motif Gender dalam Cerita "Pasa'eno"}

Cerita "Pasaeno" hanya memuat kisah asal muasal kehamilan Wesande dan peristiwa kelahiran Pasaena. Berikut analisis mitem cerita Pasaeno.

1) Wesande hamil karena meminum pohon air atoho. Wesande dituduh orang-orang berbuat asusila/berzina dengan laki-laki.

2) Wesande bersumpah: "jika aku benar telah berkumpul dengan lelaki yang menyebabkan aku hamil, apabila aku nanti melahirkan, itulah yang akan merenggut nyawaku, jika tidak, aku akan selamat umur panjang dan anakku akan menjadi orang mubarak nanti di kemudian hari."
3) Orang kampung tetap tidak percaya Wesande hamil dengan proses yang gaib.

4) Wesande diasingkan di tengah hutan.

5) Wesande melahirkan dengan selamat di pengasingan

6) Ayah bayi Wesande menurunkan perahu berisi peralatan mandi bayi dari langit.

7) Orang kampung akhirnya memercayai cerita Wesande.

8) Bayi Wesande dinamai Pasa'eno dan orang kampung menyembah Pasa'eno sebagai titisan dewa.

9) Peralatan mandi Pasa'eno diyakini masih ada hingga sekarang.

10) Pasa'eno diyakini sebagai cikal bakal orang kebanyakan (pertengahan antara anakia dan ata)

Meskipun bertajuk Pasa'eno, seorang tokoh dalam cerita yang berjenis kelamin laki-laki, inti cerita berada pada tokoh Wesande. Wesande merupakan ibunda Pasa'eno, seorang perempuan yang beroleh mukjizat dari dewata berupa kehamilan dengan cara yang tidak biasa. Ada tiga perlakuan terhadap Wesande yang menunjukkan motif gender dalam cerita Pasa'eno.

Pertama, Wesande dituduh berbuat zina dengan seorang laki-laki. Tuduhan ini diberikan tanpa dasar atau bukti apa pun. Tuduhan ini hanya didasari oleh asumsi masyarakat atas kehamilan Wesande yang tidak bersuami. Bahkan, sumpah Wesande atas nama dewa tidak membuat orang di sekitarnya memercayai perempuan ini. Padahal, Wesande sama sekali tidak pernah melakukan perbuatan zina. Kehamilannya terjadi setelah ia meminum air pohon atoho. Atas kehendak sangia (dewa), Wesande mengandung dari benih sangia yang berada di dalam air pohon atoho.

Ketidakpercayaan masyarakat atas sumpah yang diucapkan oleh Wesande ini diikuti dengan perlakuan kedua, yaitu 
ketika kehamilan Wesande semakin membesar, masyarakat mengucilkannya di hutan. Penghukuman atas kesalahan yang tidak dilakukannya ini tidak melalui proses pengadilan di mana terhukum boleh mengeluarkan pembelaannya. Dalam perspektif gender, perlakuan ini menunjukkan diskriminasi. Kedudukan Wesande sebagai perempuan yang tertuduh berbuat zina tidak mendapat keadilan dalam proses hukum. Ketidakadilan terbaca dari tidak diberinya Wesande kesempatan untuk membela diri. Masyarakat di sekitarnya secara aklamasi menuduhkan perbuatan zina tanpa saksi dan tanpa bukti. Dalam ranah hukum, seyogianya orang yang dituduh melakukan sebuah kejahatan/kesalahan diberi ruang untuk mengutarakan kebenaran versinya, baik berupa deskripsi kejadian, alibi, maupun bukti untuk mendukung penyangkalannya. Dalam kisah Pasa'eno, bahkan sumpah Wesande tidak membuat masyarakat di kampungnya mau berbesar hati menerima pembelaan diri Wesande. Namun, di dalam cerita Pasa'eno tidak ada kasus serupa yang menimpa tokoh laki-laki, kedua perlakuan ini tidak dapat dimaknai sebagai pemarginalan kaum perempuan dalam perspektif gender.

Cerita "Pasa'eno" ditutup dengan segmen saat Wesande telah melahirkan bayinya dengan selamat. Apabila dikembalikan pada isi sumpah Wesande: "jika aku benar telah berkumpul dengan lelaki yang menyebabkan aku hamil maka apabila aku nanti melahirkan, itulah yang akan merenggut nyawaku," kelahiran bayi Wesande menandakan bahwa selama ini Wesandelah yang benar dan anggapan masyarakat salah. Setelah kejadian ini, barulah orang-orang di kampung Wesande memercayainya. Terlebih, sebagai anak dari asal muasal yang istimewa, sang ayah yang tidak lain sangia di kerajaan langit mengirimkan perahu berisi peralatan mandi bayi dari langit. Kenyataan yang demikian ajaib menakjubkan orang-orang yang sebelumnya mendustakan pengakuan Wesande beralih memercayainya, bahkan, mereka turut serta menamai bayi Wesande dengan nama Pasa'eno dan menyembahnya karena dia adalah anak dewa.

Ditinjau dari perspektif gender, tidak tampak adanya pemarginalan yang disebabkan oleh perbedaan jenis kelamin. Akan tetapi, apabila ditilik dari hak reproduksi seorang perempuan yang sedang mengandung yang memerlukan tempat tinggal dan asupan makanan yang cukup, terbaca dalam kisah "Pasa'eno" bahwa masyarakat kampungnya tidak mengindahkan kondisi Wesande yang sedang hamil. Mereka justru mengusirnya ke hutan tanpa jaminan tempat tinggal dan ketersediaan makanan yang dibutuhkan selama kehamilan. Masyarakat kampung dalam cerita "Pasa'eno" tidak disebutkan secara mendetail mengenai hubungan kekerabatannya dengan Wesande. Namun, mengingat kisah ini terjadi pada zaman dahulu, dapat diasumsikan bahwa mobilitas masyarakat masih rendah. Tentunya di dalam komunitas "masyarakat kampung" ada keluarga inti Wesande (orang tua dan saudarasaudara) yang semestinya bertanggung jawab atas keselamatan Wesande. Akan tetapi, keluarga Wesande justru mengambil posisi bersama warga masyarakat lainnya untuk memojokkan Wesande.

\section{Motif Gender dalam Tiga Cerita Rakyat Tolaki}

Suku Tolaki merupakan suku yang menganut garis patriarki. Di dalam cerita Wekoila justru menampilkan tokoh utama perempuan yang cakap dalam ranah publik. Dapat disimpulkan, 
meskipun garis keturunan yang dianut oleh suku Tolaki adalah garis laki-laki, di dalamnya tidak dikenal pembedaan dalam aktualisasi diri bagi perempuan maupun laki-laki. Secara tradisional, suku Tolaki tidak mempermasalahkan jenis kelamin dalam memberi kesempatan untuk berkiprah.

Motif gender menjadi motif penyerta sepanjang kisah "Haluoleo". Motif utama cerita ini adalah motif kepahlawanan. Motif gender sebagai motif penyerta direlasikan dengan tokoh Haluoleo sebagai tokoh utamanya. Diawali dengan sejarah kelahirannya, peran dan posisi ibu cukup memberikan ilustrasi motif gender pada seksi awal cerita ini. Seksi ini mengetengahkan posisi perempuan dalam aspek regenerasi nama keluarga. Perempuan diposisikan sebagai modal bagi kesinambungan keturunan. Perspektif gender yang terbaca pada seksi ini yaitu adanya kerja sama antara laki-laki dan perempuan demi sebuah kelahiran generasi baru. Tokoh perempuan lainnya dalam cerita "Haluoleo" merupakan putri Haluoleo. Perempuan, yang direpresentasikan oleh puteri Haluoleo, memang diceritakan tenggelam dan pada akhirnya ditinggalkan oleh ayahnya. Akan tetapi, dalam delik cerita, anak perempuan ini diminta tinggal oleh Raja I'Puritahi agar ada juga berkah Haluoleo di bumi Konawe. Dari tujuan Raja I'Putitahi yang diyakini sebagai sangia penguasa alam air ini, terbaca bagaimana seorang perempuan diposisikan sebagai bagian penting untuk menjadi penyambung kebaikan orang tuanya. Dalam perspektif gender, perlakuan Haluoleo (meninggalkan puterinya) tidak merupakan tindak pemarginalan. Justru, Haluoleo memercayai puterinya untuk tetap tinggal dan membawa berkah bagi bumi Konawe. Terakhir, Putri Wolio yang merepresentasikan motif gender dari dua sisi. Pertama, sebagai objek sayembara menyiratkan bahwa perempuan adalah sesuatu yang harus diperjuangkan. Representasi ini menempatkan perempuan pada posisi superior. Akan tetapi, dari perspektif lain, objek sayembara juga menunjukkan inferioritas. Sang putri tidak berhak memutuskan jodohnya sendiri.

Pada kisah "Pasaeno", jika ditinjau dari perspektif gender, tidaklah tampak adanya pemarginalan yang disebabkan oleh perbedaan jenis kelamin. Akan tetapi, apabila ditilik dari hak reproduksi seorang perempuan yang sedang mengandung dan memerlukan tempat tinggal dan asupan makanan yang cukup, terbaca dalam kisah "Pasa'eno" bahwa masyarakat kampungnya tidak mengindahkan kondisi Wesande yang sedang hamil. Mereka justru mengusirnya ke hutan tanpa jaminan tempat tinggal dan ketersediaan makanan yang dibutuhkan selama kehamilan. Masyarakat kampung dalam cerita "Pasa'eno" tidak disebutkan secara mendetail mengenai hubungan kekerabatannya dengan Wesande. Namun, mengingat kisah ini terjadi pada zaman dahulu, dapat diasumsikan bahwa mobilitas masyarakat masih rendah. Tentunya di dalam komunitas "masyarakat kampung" ada keluarga inti Wesande (orang tua dan saudarasaudara) yang semestinya bertanggung jawab atas keselamatan Wesande. Akan tetapi, keluarga Wesande justru mengambil posisi bersama warga masyarakat lainnya untuk memojokkan Wesande.

\section{PENUTUP}

Ketiga cerita rakyat Tolaki yang melibatkan tokoh perempuan di dalamnya menunjukkan motif gender. Motif gender yang termuat di dalam cerita hadir dalam perspektif beragam. Cerita "Wekoila" menunjukkan motif 
gender bahwa tokoh perempuan diposisikan superior. Wekoila menunjukkan kiprah positif baik dalam ranah domestik maupun publik. Cerita "Haluoleo" memuat motif gender yang menggambarkan tidak ada konsep baku bagi pemosisian perempuan. Sementara itu, cerita "Pasaeno" menunjukkan motif gender bahwa tokoh perempuan ditempatkan sebagai pihak yang diabaikan hak-haknya. Dengan demikian disimpulkan bahwa motif gender dalam ketiga cerita rakyat Tolaki ini tidak memiliki keseragaman.

\section{DAFTAR PUSTAKA}

Ahimsa-Putra, Heddy Shri. (2006). Strukturalisme Levi-Strauss, mitos dan karya sastra. Yogyakarta: Kepel Press.

Danandjaja, J. (1986). Folklor Indonesia. Jakarta: Grafitipers.

Faisal. (2014). Tenun tradisional Tolaki Sulawesi Tenggara. Makassar: Pustaka Refleksi.

Hastuti, H. B. P. (2013). Representasi perempuan Tolaki dalam mitos: Studi terhadap mitos Oheo dan mitos Wekoila. Universitas Halu Oleo.

Hastuti, H. B. P. (2014a). Membaca perempuan Tolaki melalui mitos Wekoila. Alayasastra, 12 (1), 3950 .

Hastuti, H. B. P. (2014b). Mitos Oheo dan asas hubungan dalam konsep o rapu menguak posisi perempuan dalam keluarga suku Tolaki. Patanjala, 6(1), 17-32.
Maranay, H. (2006). Perahu kaca di tanah Tolaki. Surakarta: PT Pratama Mitra Aksara.

Melamba, B., Akhdan, H., Bunggulawa, Daniel J. Amaludin, M., \& Sambari, A. G. (2013). Tolaki: sejarah, identitas, dan kebudayaan. Yogyakarta: Penerbit Lukita.

Nitayadnya, I. W., Karsana, D., Pranawengtyas, D. R., \& Rahma, S. (2016). Pemetaan motif cerita rakyat Pamona, Taa, Dondo, dan Lauje di Sulawesi Tengah. Makassar: De La Macca.

Rahmawati. (2007). Analisis aktansial dan fungsional cerita saga dalam sastra lisan Tolaki. Bunga Rampai Hasil Penelitian Bahasa dan Sastra (pp. 66-149). Kendari: Kantor Bahasa Provinsi Sulawesi Tenggara.

Tarimana, A. (1993). Kebudayaan Tolaki. Jakarta: Balai Pustaka.

Taum, Y. Y. (2011). Studi sastra lisan: sejarah, teori, metode, dan pendekatan disertai contoh penerapannya. Yogyakarta: Lamalera.

Thompson, S. (1958). Motif index of folk literature (New Enlarg). Bloomington Indiana: Indiana University.

Yetti, E. (2014). Motif asal-usul tanaman padi dalam tiga cerita rakyat Indonesia. Kandai, 10 (1), 53-67. 